\section{SOI: $1.1 / \mathrm{TAS} \quad$ DOI: $10.15863 / \mathrm{TAS}$ International Scientific Journal Theoretical \& Applied Science}

\section{Sara Gulbaz \\ Dr., Senior Registrar in \\ Alkhidmat Mansoorah Hospital Lahore, Pakistan. sara.gulbaz@tih.org.pk}

p-ISSN: 2308-4944 (print) e-ISSN: 2409-0085 (online)

Sheeba Rehman

Dr., Assistant Professor at Rai Medical College Sargodha, Pakistan ahtasham.ali@gmail.com

Published: $24.09 .2018 \quad$ http://T-Science.org
Ayeman Khalid

Dr., WMO at BHU 87/6-R, Pakistan ayemankhalid@gmail.com

\title{
ROLE OF MISOPROSTOL IN PREVENTING COMPLICTIONS AFTER MISCARRIAGE
}

\begin{abstract}
Objective: This study was conducted to determine role of Misoprostol in preventing post miscarriage complications in first trimester of pregnancy.

Design and Setting: This is an observational type of prospective study. This study was carried out in Alkhidmat Mansoorah Hospital Lahore, Pakistan.

Duration of study: Study was started in July 2017 and completed in December 2017 comprising on 7 months duration.

Patients and Methods: In this study all those cases were included which presented with incomplete or missed miscarriage in first trimester of pregnancy. Dosage of $600 \mathrm{mcg}$ misoprostol was given one time for incomplete miscarriage and repeated doses of $600 \mathrm{mcg}$ were given to the females with 4 hours interval with missed miscarriage via sublingual route. Effect of misoprostol was observed in study group for 10-15 days. Only vitally stable patients were included in this study. Patients with excessive vaginal bleeding after miscarriage, abdominal pain, anemia and vitally unstable due to complications of miscarriage were not included in this study. These cases were underwent evacuation and curettage of retained products of conception. A Performa was designed containing all necessary information regarding age, duration of pregnancy, post miscarriage complications, blood loss, dosage of misoprostol, its side effects and satisfaction of patients towards this treatment.

Results: Total 75 cases were studied belonging to different age groups with minimum age of the female 21 years and maximum age of 37 years. Mean age of patients in study group was 34.5 years. Post miscarriage major complication reported was mild blood loss in 13 cases, moderate blood loss in 53 cases and severe bleeding in 12 cases was reported. Single dosage of misoprostol was given in 15 cases, double dosage given in 53 cases and three doses were given in 7 cases. After giving misoprostol its side effect reported were Nausea and vomiting in 4 cases, fever with chills in 8 cases, abdominal pain in 4 cases, diarrhea in 10 cases, flatulence in 9 females and headache was reported in 11 cases. Out of 75 cases 24 cases showed various side effects of this drug while in remaining cases no side effect was seen. In our study group 72 patients successfully responded to this management while 3 cases did not respond and surgery was undertaken in them. So success rate was $96 \%$.

Conclusion: Miscarriage is associated with various complications and out of which hemorrhage is a serious complication leading to death. These complications can be reduced by safe method of miscarriage using misoprostol via sublingual route. It is cheap and successful method.
\end{abstract}

Key words: Misoprostol uses, first trimester miscarriage, side effects of misoprostol, incomplete miscarriage.

Language: English

Citation: Gulbaz S, Rehman S, Khalid A (2018) ROLE OF MISOPROSTOL IN PREVENTING COMPLICTIONS AFTER MISCARRIAGE. ISJ Theoretical \& Applied Science, 09 (65): 154-159.

Soi: http://s-o-i.org/1.1/TAS-09-65-25 Doi: crossef https://dx.doi.org/10.15863/TAS.2018.09.65.25

\section{INTTRODUCTION}

Misoprostol is a widely used drug for inducing miscarriage. ${ }^{1}$ It is a safe method of miscarriage which reduced complications after miscarriage. It has very few side effects such as headache, nausea, vomiting and abdominal pain. Headache is a common side effect. $^{2}$ Dose of misoprostol for inducing miscarriage is $600 \mathrm{mcg}$. It is used as a single dose in incomplete miscarriage and double dose for missed miscarriage. In first trimester complications occur frequently which lead to miscarriage. This type of spontaneous miscarriage causes complications in females and severe blood loss may happen. This drug is used to prevent such complications and to reduce bleeding. ${ }^{3}$ In Pakistan, 0.89 million women experience miscarriage 
annually. Such a high prevalence of abortions necessitates proper management to reduce morbidity and mortality. After incomplete or missed abortion retained products of conception causes severe complications such as hemorrhage and septicemia. This is fatal for mothers. Immediately dilatation and curettage is required. ${ }^{4}$ This procedure is most commonly performed in gynecology wards. Inadequate resources in hospital, limitations of surgical skills and lack of skilled surgeons makes medical management most favorable in such situations. Therefore misoprostol is a drug of choice to avoid surgical treatment in many cases. It causes uterine contractions and reduces hemorrhage and causes expulsion of RPOCs. It is prostaglandin analogue easily available and cheap. Patient does not need hospital admission. ${ }^{5}$ There are various routes of its use via oral, sub lingual route, vaginal route and per rectal route. Sub lingual route is much effective. This drug is metabolized in liver and it has hepatic excretion. It is very potent and effects quickly. This drug causes gastrointestinal bleeding, its main side effect. Its efficacy depends on dosage, size of sac and diagnosis. It can be used in various doses via different routes but sublingual route is best for this purpose. $^{6}$ It was seen that this treatment was acceptable by most of the study subjects and they were satisfied by its results. Its widely use is decreasing morbidity and mortality after miscarriage and females living in remote areas far away from well developed medical facilities can be saved using this simple method. Which females have severe hemorrhage and low hemoglobin level and vitally unstable, they should undergo laparotomy because in such patients conservative treatment is not suitable. Blood transfusion is required immediately to build up HB. In severe hemorrhage main line of treatment is to prevent hypotension. ${ }^{7}$ Skilled surgeons are required to operate such cases. In this study mostly females were above 30 years of age. Parity, age, previous cesarean and gestational age determine outcome in female patients after miscarriage. It was seen that in study group most of the females delivered fetus within 24 hours after taking misoprostol while few others took $48 \mathrm{~h}, 72 \mathrm{~h}$ and one patient delivered after 86 hours. This denotes it effects quickly. Non surgical management is always accepted by most of the people as they avoid hospital stay and fear of surgery is also a major factor. ${ }^{8}$ Mild and moderate bleeding can be controlled by conservative management but heavy bleeding is indication of surgery.

\section{Patients and Methods}

It is an observational study conducted in gynaecology department of a well developed hospital. This study comprises on six months duration. In this study all those cases were included which presented with incomplete or missed miscarriage in first trimester of pregnancy. Dosage of $600 \mathrm{mcg}$ misoprostol was given one time for incomplete miscarriage and double dosage of 600 mcg was given to the females with 4 hours interval with missed miscarriage via sublingual route. Effect of misoprostol was observed in study group for 1015 days. Only vitally stable patients were included in this study. Patients with excessive vaginal bleeding after miscarriage, abdominal pain, anemia and vitally unstable due to complications of miscarriage were not included in this study. These cases were underwent laparotomy for evacuation of retined products of conception. Patients were told about the side effects of misoprostol and they were informed that complete expulsion of fetus may happen within one day, a week or two weeks and in that case they will report to the hospital immediately. A proforma was designed containing all necessary information regarding age, duration of pregnancy, post miscarriage complications, blood loss, dosage of misoprostol, its side effects and satisfaction of patients towards this treatment. In this study 75 cases were studied which presented to the hospital emergency due to miscarriage in first trimester either missed or incomplete miscarriage. Informed consent was taken from them. They were informed about non surgical and surgical treatment and then their choice was asked. All females preferred medical management. Diagnosis of missed miscarriage was established when there was no fetal cardiac activity on ultrasonography. In incomplete miscarriage pregnant female gives history of per vaginal bleeding and on examination cervical os is open.

\section{Results}

Dose of misoprostol for inducing miscarriage is $600 \mathrm{mcg}$. It is used as a single dose in incomplete miscarriage and double dose for missed miscarriage. In first trimester complications occur frequently which lead to miscarriage. In this study all those cases were included which presented with incomplete or missed miscarriage in first trimester of pregnancy. Dosage of $600 \mathrm{mcg}$ misoprostol was given one time for incomplete miscarriage and double dosage of $600 \mathrm{mcg}$ was given to the females with 4 hours interval with missed miscarriage via sublingual route. Total 75 cases were studied belonging to different age groups with minimum age of the female 21 years and maximum age of 37 years. Mean age of patients in study group was 34.5 years. Post miscarriage major complication reported was mild blood loss in 13(17.3\%) cases, moderate blood loss in 53(66.7\%) cases and severe bleeding in $12(16 \%)$ cases was reported. Single dosage of Misoprostol was given in $15(20 \%)$ cases, double dosage given in $53(70.6 \%)$ cases and three doses were given in $7(9.3 \%)$ cases. After giving 


\begin{tabular}{l|lr|ll|ll} 
& ISRA (India) & $=\mathbf{1 . 3 4 4}$ & SIS (USA) & $=\mathbf{0 . 9 1 2}$ & ICV (Poland) & $=\mathbf{6 . 6 3 0}$ \\
Impact Factor: & ISI (Dubai, UAE) $=\mathbf{0 . 8 2 9}$ & PUHЦ (Russia) $=\mathbf{0 . 1 5 6}$ & PIF (India) & $=\mathbf{1 . 9 4 0}$ \\
& GIF (Australia) & $\mathbf{0 . 5 6 4}$ & ESJI (KZ) & $=4.102$ & IBI (India) & $=\mathbf{4 . 2 6 0}$ \\
& JIF & $=\mathbf{1 . 5 0 0}$ & SJIF (Morocco) & $=2.031$ & & \\
\hline
\end{tabular}

misoprostol its side effect reported were Nausea and vomiting in $4(5.3 \%)$ cases, fever with chills in $8(10.7 / 5)$ cases, abdominal pain in $4(5.3 \%)$ cases, diarrhea in $10(13.3 \%)$ cases, flatulence in $9(12 \%)$ females and headache was reported in $11(14.7 \%)$ cases. Out of 75 cases $24(32 \%)$ cases showed various side effects of this drug while in remaining cases no side effect was seen. Out of 75 cases of study group $69(92 \%)$ were satisfied with treatment while $6(8 \%)$ were not satisfied similarly $70(93.3 \%)$ cases showed acceptability while in $5(6.7 \%)$ cases it was not acceptable.

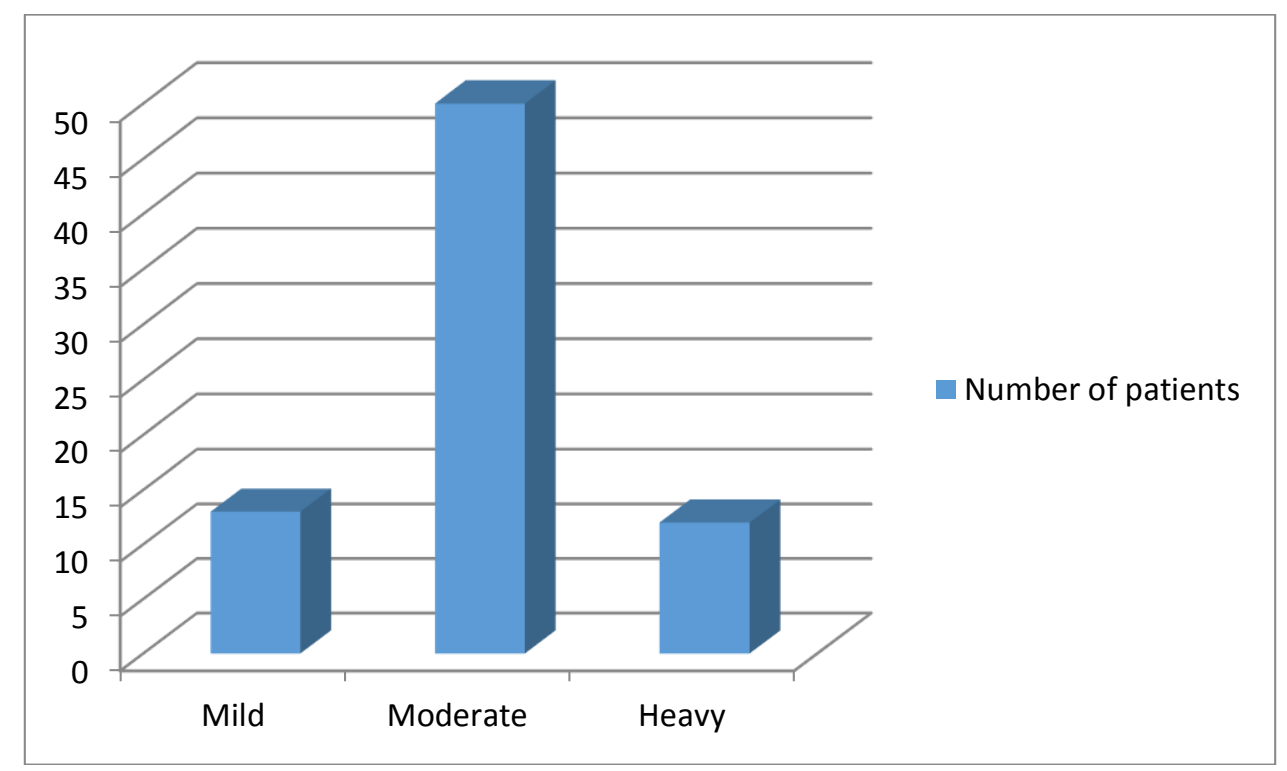

Figure-1 Frequency distribution of patients in study group on the basis of post miscarriage bleeding

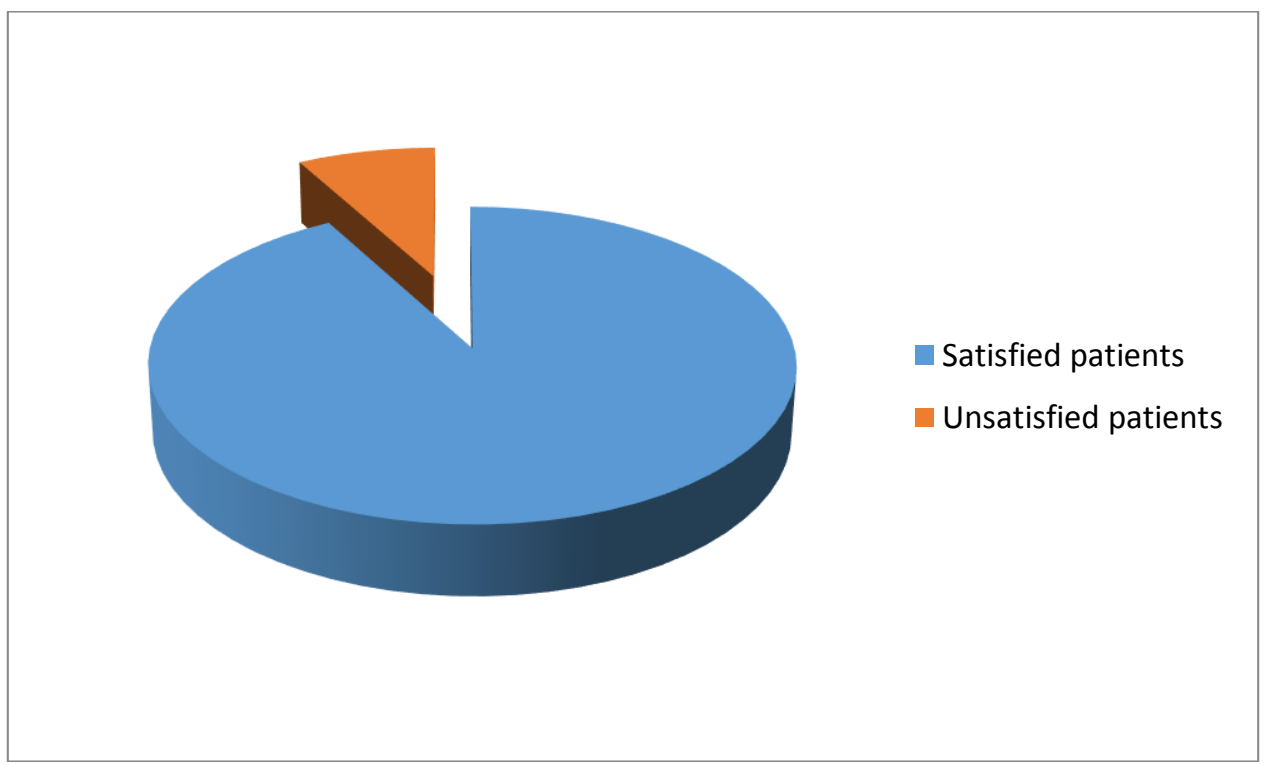

Figure-2 Satisfaction level of patients from misoprostol in study group 


\begin{tabular}{l|lr|ll|ll} 
& ISRA (India) & $=\mathbf{1 . 3 4 4}$ & SIS (USA) & $=\mathbf{0 . 9 1 2}$ & ICV (Poland) & $=\mathbf{6 . 6 3 0}$ \\
Impact Factor: & ISI (Dubai, UAE) $=\mathbf{0 . 8 2 9}$ & PUHЦ (Russia) $=\mathbf{0 . 1 5 6}$ & PIF (India) & $=\mathbf{1 . 9 4 0}$ \\
& GIF (Australia) & $\mathbf{0 . 5 6 4}$ & ESJI (KZ) & $=4.102$ & IBI (India) & $=\mathbf{4 . 2 6 0}$ \\
& JIF & $=\mathbf{1 . 5 0 0}$ & SJIF (Morocco) & $=2.031$ & & \\
\hline
\end{tabular}

Age distribution of females in study group

Table-1

\begin{tabular}{|c|c|c|}
\hline Age of patients (years) & Number of Patients & \% \\
\hline $20-25$ & 9 & 12 \\
\hline $26-30$ & 22 & 29.3 \\
\hline $31-35$ & 31 & 41.3 \\
\hline $36-40$ & 13 & 17.3 \\
\hline Total & $\mathbf{7 5}$ & $\mathbf{1 0 0}$ \\
\hline
\end{tabular}

Table-2

Estimated blood loss after miscarriage

\begin{tabular}{|c|c|c|}
\hline Post miscarriage blood loss & Number of Patients (n) & \% \\
\hline Mild & 13 & 17.3 \\
\hline Moderate & 50 & 66.7 \\
\hline Heavy & 12 & 16 \\
\hline
\end{tabular}

Table-3

Side effects of sublingual use of Misoprostol among study subjects

\begin{tabular}{|c|c|c|}
\hline Side Effects & Number of Patients (n) & $\%$ \\
\hline Nausea/ vomiting & 4 & 5.3 \\
\hline Diarrhea & 10 & 13.3 \\
\hline Fever with Chills & 8 & 10.7 \\
\hline Headache & 11 & 14.6 \\
\hline Abdominal Pain & 4 & 5.3 \\
\hline Flatulence & 9 & 12 \\
\hline
\end{tabular}

\section{DISCUSSION}

This study was done to determine role of misoprostol in first trimester miscarriage. Medical management is acceptable by population more than surgical management. ${ }^{9}$ People are afraid of surgery and its outcome. No doubt surgical option should not be used initially rather first of all patient should be given medical treatment and in case of failure of this surgical option should can be used. After operation patient has to face more morbidity and disability for a long period of time. There is physical and financial burden. That's why conservative treatment using sublingual misoprostol is a treatment of choice. It is given in a dose of $600 \mathrm{mcg} .{ }^{10,11}$ One dose in case of incomplete abortion and two doses are given with the interval of 4 hours in case of missed abortion. This drug is prostaglandin analogue and causes contraction of uterine muscles which expels fetus out and complete abortion occurs. Muscular contraction prevents excessive bleeding which is a serious complication after miscarriage and if not managed may lead to death of female. ${ }^{12}$ After taking it delivery may occur in first 24 or 48 hours and may be delayed after 72 hours in some cases. Success rate 
in our study was $96 \%$ which proves this treatment highly successful. Another studies done in China showed success rate of $87.5 \%$ in which misoprostol was given sublingually and vaginally. According to a study done in India success rate was $86 \%$. Our study showed much higher rate of success. ${ }^{13-15}$ Misoprostol is a widely used drug for inducing miscarriage. It is a safe method of miscarriage which reduced complications after miscarriage. It has very few side effects such as headache, nausea, vomiting and abdominal pain. Headache is a common side effect. Dose of misoprostol for inducing miscarriage is 600 mcg. It is used as a single dose in incomplete miscarriage and double dose for missed miscarriage. In first trimester complications occur frequently which lead to miscarriage. It is an observational study conducted in gynaecology department of a well developed hospital. This study comprises on six months duration. ${ }^{16}$ In this study all those cases were included which presented with incomplete or missed miscarriage in first trimester of pregnancy. Mean age of patients in study group was 34.5 years. Post miscarriage major complication reported was mild blood loss in $13(17.3 \%)$ cases, moderate blood loss in $53(66.7 \%)$ cases and severe bleeding in $12(16 \%)$ cases was reported. Single dosage of Misoprostol was given in $15(20 \%)$ cases, double dosage given in $53(70.6 \%)$ cases and three doses were given in $7(9.3 \%)$ cases. After incomplete or missed abortion retained products of conception causes severe complications such as hemorrhage and septicemia. This is fatal for mothers. Immediately dilatation and curettage is required. This procedure is most commonly performed in gynecology wards. ${ }^{17}$ This drug causes gastrointestinal bleeding, its main side effect. Its efficacy depends on dosage, size of sac and diagnosis. It can be used in various doses via different routes but sublingual route is best for this purpose. It was seen that this treatment was acceptable by most of the study subjects and they were satisfied by its results. Its widely use is decreasing morbidity and mortality after miscarriage and females living in remote areas far away from well developed medical facilities can be saved using this simple method. ${ }^{18-20}$ A study done by Woods and Grazio proved high satisfaction among patients for this treatment. Before giving this treatment to the patient proper counseling should be done and pros and cons should be mentioned as this is a right of the patient to be well informed about the options of treatment and then decision should be left over him freely to choose any option.

\section{CONCLUSION}

Miscarriage in first trimester frequently occurs in females which has many complications. A conservative treatment to treat such complications is always on priority than surgical management. Use of misoprostol is very effective for such patients with minimum side effects and high acceptability and success rate. Failure of medical management indicates surgical option. Proper counseling of patients about its side effects is necessary.

\section{References:}

1. Nielsen, S. and Hahlin M. (1995) Expectant management of fi rst tri-mester spontaneous abortion. Lancet, 1995; 345: 84-6.

2. (2001) World Health Organization, United Nations Children's Funds, United Nations Population Funds, Maternal mortality in 1995.Geneva: World Health organization: 2001

3. Sattar ZA, Singh S, Faryal F. (2007) Estimating the incidence of abor-tion in Pakistan. Stud Fam Plann 2007;38:11-22.

4. (1985) Joint study of Royal College Of General Practitioner and Royal College Of Obstetrician and Gynaeocologist. induc-tion abortion operations and their early sequel. J R Coll Gen Pract.1985;35: 175-80.

5. Petrous S, Trinder J, Broklehurst P, Smith L. (2006) Economic evalu-ation of alternative management methods of fi rst trimester miscarriage based on results of MIST trial.BJOG 2006; 113:879-89

6. Jurkovic D, Ross JA, Nicolaides KH. (1998) Expectant managent of missed miscarriage. $\mathrm{Br} \mathrm{J}$ Obstet Gynaecol 1998; 105: 670-1.

7. Luise C, Jermy K, May C, Costello G, Collins WP, Bourne TH. (2002) Outcome of expectant management of spontaneous fi rst trimester miscarriage : observational study. BMJ 2002; 324:873-5.

8. Chia KV, Oqbo VI. (2002) Medical termination of missed abortion. J Obstet Gynaecol 2002; 19: 266-71.

9. Tango OS, Schweer H, Seyberth HW, Lee SWH, HO PC. (2002) Phar-macokinetics of 


\begin{tabular}{l|lr|ll|ll} 
& ISRA (India) & $=\mathbf{1 . 3 4 4}$ & SIS (USA) & $=\mathbf{0 . 9 1 2}$ & ICV (Poland) & $=\mathbf{6 . 6 3 0}$ \\
Impact Factor: & ISI (Dubai, UAE) $=\mathbf{0 . 8 2 9}$ & PUHЦ (Russia) $=\mathbf{0 . 1 5 6}$ & PIF (India) & $=\mathbf{1 . 9 4 0}$ \\
& GIF (Australia) & $\mathbf{0 . 5 6 4}$ & ESJI (KZ) & $=4.102$ & IBI (India) & $=\mathbf{4 . 2 6 0}$ \\
& JIF & $=\mathbf{1 . 5 0 0}$ & SJIF (Morocco) & $=2.031$ & & \\
\hline
\end{tabular}

different routes of administration of misoprostol. Hum Reprod 2002;17: 332-6.

10. Tang OS, Miao BY, Lee SWH, Ho PC. (2002) Pilot study on the use of repeated doses of sublingual misoprostol in termination of pregnancy uo to 12 weeks gestation: efficacy and acceptabil-ity; Hum Reproduction 2002; 17: 654-8.

11. Aronson A, Helstrom L, Gemzell-Danielson K. (2004) Sublingual compared with oral misoprostol for cervical dilatation prior to vaccum aspiration: a randomized comparison. Contracep-tion 2004:69(2) :165-9.

12. Von Hertzen H, piaggio G, Huong NTM, et al. (2007) misoprostol for termination of early pregnancy-a randomized multicentre equivalence trial on two routes and two intervals. Geneva : WHO; 2007.

13. Dao B, Blum J, Theiba B, Rhagavan S, et al. (2007) Is misoprostol safe, effective and acceptable alternative to manual vacuum aspiration for post abortion care? Results from a randomized trial Burkina Fasco, West Africa. Br J Obstet Gynaecol 2007; 114:1368-75.

14. Bique C, Usta M, Debora B, chong E, et al. (2007) Comparison of misoprostol and manual vacuum aspiration for the treatment of incomplete abortion. Int J Gynecol Obstet 2007; 98(3) :222-6.
15. Tang OS, Lau WN, Ng EH, Lee SW, Ho PC. (2003) A prospective ran-domized study to compare the use of repeated doses of vaginal with sublingual misoprostol in management of fi rst trimester silent miscarriage. Hum Repro 2003; 18: 176-81

16. Sharma D, Singhal SR., Rani XX. (2007) Sublingual misoprostol in management of missed abortion in India. Trop Doc 2007;37: 39-40.

17. Bano K, Talat, Iqbal S. (2009) Alternatives to surgical evacuation of uterus: misoprostol for post-abortion care. Journal of Surgery Pakistan 2009;14(2): 53-57.

18. Blanchard K, Taneepanichskul, Kiriwat O, et al. (2004) Two regimen of misoprostol for treatment of incomplete abortion. Obstet Gynecol 2004; 103: 860-5.

19. Weeks A, Alia G, Blum J, et al. (2005) A randomized trial of oral miso-prostol versus manual vacuum aspiration for the treatment of incomplete abortion in Kampala, Uganda. Obstet Gynecol 2005 ; 106: 540-7.

20. (2009) WHO Clinical Guidelines Bellagio, Italy in Feb 2007 Gemzell-Danielsson et al., Int J Gynecol Obstet(2007) 99, S182-S185 FIGO October 2009. 